\title{
Article
}

\section{Developmental associations between victimization and body mass index from 3 to 10 years in a population sample}

Qualter, Pamela, Murphy, Suzanne M., Abbott, Janice, Gardner, Kathryn J., Japel, Christa, Vitaro, Frank, Boivin, Michel and Tremblay, Richard E.

Available at http://clok.uclan.ac.uk/11674/

Qualter, Pamela, Murphy, Suzanne M., Abbott, Janice ORCID: 0000-0001-98511236, Gardner, Kathryn J., Japel, Christa, Vitaro, Frank, Boivin, Michel and Tremblay, Richard E. (2015) Developmental associations between victimization and body mass index from 3 to 10 years in a population sample. Aggressive Behavior, 41 (2). pp. 109-122. ISSN 0096-140X

It is advisable to refer to the publisher's version if you intend to cite from the work. http://dx.doi.org/10.1002/AB.21580

For more information about UCLan's research in this area go to

http://www.uclan.ac.uk/researchgroups/ and search for <name of research Group>.

For information about Research generally at UCLan please go to http://www.uclan.ac.uk/research/

All outputs in CLoK are protected by Intellectual Property Rights law, including Copyright law. Copyright, IPR and Moral Rights for the works on this site are retained by the individual authors and/or other copyright owners. Terms and conditions for use of this material are defined in the policies page. 
Running Head: VICTIMISATION AND OBESITY: LONGITUDINAL ASSOCIATIONS 1

Developmental Associations between Victimization and Body Mass Index from 3 to 10 years in a Population Sample

Pamela Qualter $^{1,7}$, Suzanne M. Murphy ${ }^{2}$, Janice Abbott ${ }^{1}$, Kathryn J. Gardner ${ }^{1}$, Christa Japel ${ }^{3,7}$, Frank Vitaro ${ }^{4,7}$, Michel Boivin ${ }^{5,7}$, and Richard E. Tremblay ${ }^{6,7,8,9 .}$

1 School of Psychology, University of Central Lancashire, Preston, Lancashire, UK

2 Institute of Health Research, University of Bedfordshire, Hitchin Road, Luton, UK

3 Université du Québec à Montréal (UQAM), Canada

4 School of Psycho-education, Université de Montréal, Montréal, Québec, Canada

5 School of Psychology, Université Laval, Québec City, Québec, Canada

6 Departments of Pediatrics, Psychiatry, and Psychology, Université de Montréal, Montréal, Québec, Canada

7 Research Unit on Children’s Psychosocial Maladjustment (GRIP), which is a multiuniversity (Université de Montréal, Université Laval, and McGill University) research centre. 8 School of Public Health, Physiotherapy and Population Sciences, University College Dublin, Ireland.

9 International Laboratory for Child and Adolescent Mental Health Development, INSERM, U669, Paris, France.

Correspondence and reprint requests to Pamela Qualter, School of Psychology, University of Central Lancashire, UK, PR1 2HE: Tel: (+044) 01772 893877; E-mail: PQualter@uclan.ac.uk 


\begin{abstract}
In the current prospective study, we investigated (1) whether high and low BMI in early childhood puts a child at risk of victimization by their peers, and (2) whether being victimised increases BMI over the short- and long-term, independent of the effect of BMI on victimization. We also examined whether gender moderated these prospective associations. Participants were 1344 children who were assessed yearly from ages 3 -10 years as part of the Québec Longitudinal Study of Child Development (QLSCD). BMI predicted annual increases in victimization for girls aged 6 years and over; for boys aged 7 and 8 years of age, higher BMI reduced victimization over the school year. Further, victimization predicted annual increases in BMI for girls after age 6 years. When these short-term effects were held constant, victimization was also shown to have a three and five-year influence on annual BMI changes for girls from age 3 years. These short- and long-term cross-lagged effects were evident when the effects of family adversity were controlled. The findings support those from previous prospective research showing a link between higher BMI and victimization, but only for girls. Further, being victimised increased the likelihood that girls would put on weight over time, which then increased future victimization. The implications of these prospective findings for interventions are considered.
\end{abstract}

Key words: BMI; Obesity; Overweight; Victimization; Bullying; Longitudinal Study; Crosslagged analyses. 


\section{Introduction}

Peer victimization has consistently been shown to have significant short- and long-term deleterious psychological impacts, with victims of peer aggression at heightened long-term risk of suicidal and self-injurious behavior (Winsper, Lereya, Zanarini \& Wolke, 2012), psychotic symptoms (Schreier et al, 2009) and depression (Ttofi, Farrington, Losel \& Loeber, 2011). There is also evidence that obesity and weight issues (including underweight) are linked with victimization, but little is know about cause and effect: obese and overweight children are often the recipients of aggression from peers (Falkner et al., 2001; Janssen, Craig, Boyce, \& Pickett, 2004; Lumeng et al., 2010; Pearce, Boegers, \& Prinstein, 2002; Wang, Iannotti, \& Luk, 2010), but is it also the case the being victimised by peers leads to weight related problems?

Body mass index (BMI) is one commonly used measure of obesity. The research evidence linking BMI to victimization is predominately based on cross-sectional data with few short-term longitudinal studies. This provides an incomplete picture of events because most developmental theories view development (1) as a process driven by interactions between the child and his or her environment that can change over time (Cicchetti \& Lynch, 1993; Sameroff \& Chandler, 1975; Sameroff \& Mackenzie, 2003), and (2) argue that these processes can only be examined through longitudinal investigation that facilitates the study of bidirectional effects between individuals and social contexts and the identification of developmental periods where the child or the context is most open to change (Sameroff \& Mackenzie, 2003). According to the transactional model, developmental outcomes progress as a function of the dynamic, continuous interplay between the child and his or her social context over time (Sameroff \& Chandler, 1975; Sameroff \& Mackenzie, 2003). The model emphasises the importance of measuring the associations between constructs over many years at frequent, regular intervals (Sameroff, 2009). Within this theoretical framework, the 
influence of one construct on another can occur over a period of time, such that events taking place at one time point can influence outcomes many years later. Thus, when considering the possible relations between BMI and peer victimization, a number of processes may be taking place that are not captured by cross-sectional research. First, it is possible that there are unidirectional effects only over time, with the child's high or low BMI appearance drawing unfavourable attention from peers, leading to victimization. Another possibility is that both BMI and victimization affect each other, but the influence of each on the other could remain steady or vary in strength at different times and ages. It is also possible that, over time, BMI and victimization become mutually and exponentially reinforcing, leading to a spiralling increase in both these processes. Thus, from the transactional perspective, without longitudinal studies, there remain important gaps in our knowledge about the developmental relations between the BMI and victimization.

Evidence from cross-sectional research shows that the social context is often hostile for obese and overweight children and adolescents, who are regularly stigmatized, face social exclusion, discrimination and teasing by peers (Eisenberg, Neumark-Sztainer, Haines, \& Wall, 2006; Gibson, Byrne, Blair, Davis, Jacoby, \& Zubrick, 2008; Janssen et al., 2004; Latner \& Stunkard, 2003; Lumeng et al., 2010; Pearce et al., 2002; Puhl \& Brownell, 2001; Strauss \& Pollack HA, 2003). Overweight and obese children and adolescents are also stereotyped as lazy, ugly and stupid (Latner \& Stunkard, 2003; Wardle, Volz, \& Golding 1995; Zeller, Reiter-Purtill, Ramey, 2008). The stigma and negative stereotypes associated with high BMI often translate, over time, into poor quality friendships and romantic relationships for obese and overweight children and adolescents (Pearce et al., 2002; Boneberger, Von Kries, Milde-Busch, Bolte, Rochat, \& Rückinger, 2009; Bowker, Spencer, \& Salvy, 2010; Falkner et al., 2001; Griffiths \& Page, 2008; Zeller et al., 2008). It appears, then, that stereotypes about high BMI may lead overweight and obese 
children and adolescents to be rejected from the peer group and this in turn leads to victimization, contributing further to social and emotional problems (Boivin, Hymel, \& Bukowski, 1995), and increases in weight. There is also evidence that victimization increases the likelihood that the person will become overweight or obese regardless of initial BMI, suggesting that victimization is related to behavior that exacerbates weight-gain, such as binge-eating and avoidance of exercise (Faith, Leone, Ayers, Heo, \& Pietrobelli, 2002; Jensen and Steele, 2009; Neumark-Sztainer et al., 2002). Such coping strategies have the greatest impact on BMI, and thus, health, for adolescents who are already overweight or obese.

There is also evidence that adolescent girls with low BMI are victims of aggression from their peers (Wang et al., 2010). Vaillancourt (2013) argues that the peer social context is often hostile for thin adolescent girls because their thinness is a marker for youth and attractiveness, which signals higher mate value; thin attractive female adolescents often find themselves victims of indirect aggression, which is used as an intrasexual competition strategy. We know of no studies that examine longitudinally how lower BMI relates to victimization, but there is a need to examine the curvilinear relations between BMI and victimization across time so that the bidirectional relations between both low and high BMI and victimization can be examined. It is likely that the victimization of thin girls is not evident until adolescence when intrasexual competition strategies first start to be used. However, it is important to investigate different stages of development to determine how and at what point in development lower than average BMI is associated with victimization.

The few existing prospective studies that have examined weight and peer victimization showed that they affected one another over time, such that higher BMI predicted victimization, which then increased body mass (Eisenberg et al., 2006; Griffiths, et al, 2006; Mamun et al., 2012; Sweeting, et al., 2005). However, these studies have only a few waves of data collection, which does not allow for a full, complete examination of the longitudinal 
relations between weight and victimization over time in line with the transactional models of development (Sameroff, 2009). In these studies, measurements of BMI and victimization were taken either at two time points (Eisenberg et al., 2006; Griffiths et al, 2006; Mamun et al, 2013; Sweeting et al., 2005) or three time points only (Adams \& Bukowski, 2008). The number of time points included in such studies has major implications for our understanding of the way in which the relations between victimization and BMI may unfold over time. Guided by the transactional model, the present study examined longitudinal, reciprocal relations between BMI and victimization in a child sample and took measurements every year between the ages of 3 and 10 years of age. We expected to observe transactional bidirectional effects between BMI and victimization.

Ecological models (e.g., Bronfenbrenner, 1979) alert researchers to consider, not only the child's immediate environment in which she or he interacts, but also the influence of more distal social variables and how these impact development. These variables relate to the child's home, school or neighbourhood, parent's social and occupational networks and national and cultural influences. Consideration of the ecology within which the relations between BMI and victimization operate necessitates that more distal variables that are known to have an impact on obesity or victimization are measured. Known risk factors for victimization are low income (Barker, Boivin, \& Brendgen, 2008), and family composition, i.e., being a lone parent (Gibson, Byrne, Davis, Blair, Jacoby, Zubrick, 2007). Known risk factors for obesity include low income and maternal education (Grow, Cook, Arterbarn, Saelens, Drewnowski, Lozano, 2010). Previously, these variables were not included as controls in longitudinal research examining the prospective relations between BMI and victimization. These variables are examined in the current study and used in the modelling of relations between BMI and victimization over time.

\section{Examination of the prospective association between BMI and victimization in}




\section{young children.}

There are no studies that examine how the associations between BMI and victimization unfold from the earliest major peer encounters during pre-school, when children begin to experience conflicted and coercive relationships with peers (Tremblay, 2000). Prior studies have focused on the school age period only, when children's difficulties with peers are already present. However, we know very little about the association between BMI and peer victimization at a time when children are encountering their first major social context outside of the home.

There are indications in the existing literature that BMI influences the peer social context in very early childhood. For example, Brylinsky and Moore (1994) reported that negative ratings for ‘chubby’ body types increase between age 5-10 years and begin to appear at around 6-7 years of age. Turnbull, Heaslip and McLeod (2000) found that children aged 2.5 to 5 years-old rated 'fat' female doll figures (but not 'fat' male doll figures) more negatively than average-sized ones. In addition, prospective research has examined the social outcomes of high BMI for young children and shown an association between obesity and emotional and behavioral problems, including peer problems, in very young children aged 3-5 years (Griffiths, Dezateux, \& Hill, 2011). These studies indicate that significant changes may be occurring in children's attitudes to weight, high BMI, and gender in the age range from 3 to ten years, substantiating a focus on this age group in the current study.

\section{The gender-moderated hypothesis}

We expected the prospective association between BMI and victimization to be moderated by gender for two reasons. First, previous research shows that gender stereotypes about weight are important to girls long before adolescence, with preadolescent girls aged 6-7 and 9-11 years rating thinness as attractive (Brylinksy \& Moore, 1994; Tang-Péronard \& Heitman 2008). This suggests that even young girls may be susceptible to gender stereotypes 
in which the socio-cultural ideal of beauty emphasizes thinness for women and female adolescents (Puhl \& Brownell, 2001). Given that girls are particularly vulnerable to the negative social effects of high BMI even at a young age, and experience more rejection and victimization from the peer group in relation to this than boys after the age of seven years, we examined the relations between BMI and victimization in both sexes. We surmised that it was unlikely that thin girls would be victimized within the current sample because girls of this age are not usually motivated by intrasexual competition (Vaillancourt, 2013). Nonetheless, we explored whether there were curvilinear relations between BMI and victimization as a possibility that the social-cultural ideal of 'beauty as thinness' motivated young girls to victimize not just girls high on BMI, but also what they perceive as very attractive (thin) females.

A second reason for our focus on gender concerns a body of research evidence that shows gender differences in children’s aggressive behavior. Victimization in general can take a variety of forms, such as physical aggression, verbal abuse (name-calling, teasing) or more indirect, relational forms such as exclusion or rumour-spreading. Consistent gender differences have been found in the rates with which children and adolescents perpetrate physical aggression, with boys of all ages showing higher rates than girls (Archer, 2004; Card, Stucky, Sawalami \& Little, 2008). Meta-analyses by Card et al. (2008) also showed significant but weak tendencies for girls to use indirect aggression more than boys. There are also age-related trends in the types of aggressive behavior employed, with children below the age of six using more direct forms of aggression (Björkqvist, Österman, \& Kaukiainen, 1992; Monks, Ortega, \& Torrado, 2002). Given these past findings, we used a measure of overt aggression in early childhood to assess victimization, but at six years and above, the victimization measure included items related to indirect aggression.

\section{Study Aims}


There is cross-sectional and prospective evidence of associations between higher BMI and victimization in children aged more than seven years, pre-adolescence and adolescence, but there are no examinations of these relations in children below that age. Further, there are no prospective examinations of lower BMI and victimization, and no studies utilising longitudinal designs that examine bidirectional effects between BMI and victimization over more than 3 years. In the current study, we used a longitudinal design over seven years with annual data collection for children aged three-to-ten years. We first used curvilinear analyses to investigate whether higher and lower BMI puts a child at risk of victimization by their peers. Following that examination, we used a cross-lagged panel analyses to examine the relations between BMI and victimization over time, which allowed for accurate estimates of cross-time effects that linked BMI and victimization and used appropriate controls for withintime associations and stability coefficients. Family adversity variables known to impact victimization and/or BMI were included in the models. Multi-group analysis was used to examine the possibility that cross-time effects between BMI and victimization were different between gender.

\section{Method}

\section{Participants and Procedure}

The participants were part of the Québec Longitudinal Study of Child Development (QLSCD). The QLSCD is a prospective study of children, who were selected from the master registry of live births compiled by the Ministry of Health and Social Services of the Province of Québec (Canada). The target population included all singleton infants between 59- 60 gestational weeks of age who were born in Québec, between October 1997 and July 1998. Exclusion criteria included being born at less than 24, or more than 42, weeks of gestation; gestation that could not be determined from the birth records; and being born in Cree or Inuit territories, Native Canadian reserves, or northern Québec. 
A total of 2940 infants were selected for QLSCD through a region-based stratified sampling design, of which 2120 infants (48.8\% girls) took part in at Time 1 by providing informed consent. The current study used data from the fourth annual wave of data collection (T4) through to the tenth wave of data collection (T10) ${ }^{1}$ from the QLSCD. By T4, when the children were on average 3.4 years of age, 1950 participants provided data; by T10, when the children were on average 10.1 years of age, 1334 participants provided data. In order to minimize the bias associated with missing data, we used the expectation maximization (EM) algorithm to impute missing data (Schafer \& Graham, 2002). Only individuals who participated in five out of the seven measurement waves from the $4^{\text {th }}-10^{\text {th }}$ wave of data collection were included in the present study, and a total of 1344 children (girls = 706; boys = 638) met these criteria. Participants with and without complete data were compared using Little’s (1988) Missing Completely At Random (MCAR) test. This yielded a non-significant chi-square value $\left(\chi^{2}(29051)=20626.26, n s\right)$, suggesting that missing values could be reliably estimated. As a result, analyses within the current study were conducted on data from this sample of 1344 participants.

\section{Measures}

\section{Body Mass Index (BMI)}

A trained interviewer measured children's height and weight at home at each data collection period (as per Desrosiers, Dubois, \& Bédard, 2005; Dubois \& Girard, 2007). A standardized protocol was followed when height and weight were measured, with participants wearing their clothes, but not wearing their shoes. BMI was calculated as weight $[\mathrm{kg}] / \mathrm{height}$ $[\mathrm{m}]^{2}$, and these BMI values were converted to BMI z-scores using national reference data to adjust for age and sex. The practice of standardizing BMI score based on age- and sexspecific growth charts is recommended by the Centers for Disease Control and Prevention

\footnotetext{
${ }^{1}$ This tenth wave of data collection is noted as T11 in the QLSCD archive because it occurs two years after the previous time point (T9). For ease of understanding, we refer to this time point as T10 in the current paper.
} 
(Hammer, Kraemer, Wilson, Ritter, \& Dornbusch, 1991). The standardisation of the BMI scores means that any normal differences between age or gender groups are controlled in the analyses; this means we know that any effects we might find are down to real, observable across-time associations between BMI and victimization and not natural, expected differences in BMI between genders and age groups. For the analyses, the adjusted BMI measure (i.e., BMI-z-scores) was used as a continuous variable.

\section{Repeated Measures of Peer Victimization}

When measuring victimization, self-reports are generally considered the most accurate because they access the views of victims themselves (Bierman, 2004). However, at young ages, children lack the ability to interpret their peers’ intentions towards them accurately and may not yet have developed adequate cognitive abilities to understand the concepts being assessed (Ladd \& Kochenderfer-Ladd, 2002; Measelle, Ablow, Cowan \& Cowan, 1998). Monks, Smith and Swettenham (2003) have reported that children aged four to six years generally are inconsistent and unreliable at identifying victims of aggression. Further, there is evidence that young children are more likely to discuss peer problems with adults than are older children (Card et al, 2008; Shakoor et al., 2011), which indicates that adults have the available information to act as informants of young children's victimization experiences. Given this evidence, researchers have tended to rely on teacher- or parent-reports of victimization for younger children, but use peer- and self-reports for older children (Card et al, 2008).

Peer victimization during preschool. Based on the previous research we chose to assess peer victimization during preschool through mother ratings when the child was aged 3, 4, and 5 years old. The questions asked about general victimization and were not specific to weight-related victimization. The mothers were asked 'In the past 6 months, how often would you say that your child was (1) made fun of by other children, (2) hit or pushed by other 
children, and (3) called names by other children?'. Mothers rated these items on a 3-point scale $(0=$ never, $1=$ sometimes, $2=$ often $)$. Within each year, these item scores were summed and averaged to obtain a global score of peer victimization. Cronbach's alphas for the scale at each of the time points used in the current study are detailed in Table 2.

Peer victimization in school. When the child was 6, 7, 8 and 10 years of age, we asked children to provide self-ratings of victimization during structured interviews. The questions were general and were not specific to weight-related victimization. Children were asked to rate the following 5 items, using a 3-point scale ( $0=$ never, $2=$ often): Does it ever happen that (1) some children at school call you names or say bad things to you? (2) some children at school say bad things behind your back to other children? (3) a child at school will not let you play with his/her group? (4) a child at school pushes, hits, or kicks you? or (5) a child at school teases you in a mean way? Within each year, these item scores were summed and averaged to obtain a global score of peer victimization. Cronbach’s alpha for the full scale at T7 through to T10 are detailed in Table 2.

\section{Covariates}

Mothers provided information at each time point on family adversity variables as follows: family structure ( $0=2$ parents, $1=1$ parent $)$, mothers' level of education $(0=$ at least high school education; 1 = no high school education), and insufficient household income (calculated as a categorical variable to reflect Statistics Canada's definition of low income whilst taking into account the number of people in the household and the family zone of residence: coded as sufficient (0) or not (1). A composite score of these variables was not used in the analyses; instead, the association between each of these variables and BMI and victimization at the same time point was examined.

\section{Data Analysis Plan}

Cross-lagged panel analysis was used to examine both cross-sectional and longitudinal 
influences on BMI and victimization. The control variables (family structure [lone parenting], mothers' level of education, and insufficient household income) were also included in the model. We used multi-group panel analyses to investigate (1) whether higher BMI puts a child at risk of short-and long-term victimization, (2) the degree to which victimization has long- and short-term effects on BMI independent of any reciprocal effects of BMI on victimization, and (3) whether the same effects are evident for males and females. Crosslagged panel analysis is a practical analytic solution for answering these questions because it allows modelling of short- and long-term effects of BMI on victimization, and vice versa. By including family adversity variables previously found to correlate with BMI and/or victimization in our study design, we provided an opportunity to examine comprehensively the associations between BMI and victimization over time.

Cross-lagged panel analyses with observed variables were performed in AMOS 17 (Arbuckle, 2008). All analyses were conducted using full information maximum likelihood estimation with robust standard errors (Little \& Rubin 1987). First, correlational analyses were conducted to examine the within-time and across-time relations between BMI and victimization. Further, the association between these variables and the covariates were examined. These examinations were conducted separately for boys and girls to investigate whether the same patterns of effects were evident. We also examined whether the within-time and across-time relations between BMI and victimization were linear or curvilinear using quadratic regression to establish whether victimization was a characteristic of both high and low BMI scorers. Following these analyses, we conducted cross-lagged analyses, looking, first, at the baseline panel model with within-time associations and stability coefficients. Family adversity control variables were included in the model. In Stage II of the model testing, we included the cross-lagged effects in the model; within-time associations and stability coefficients and significant covariates (family adversity variables) remained in the 
model, which allowed an examination of the cross-lagged effects of BMI and victimization whilst controlling for the effects of within-time associations and stability of the constructs over time, and the effects of family adversity variables. We used multi-groups analyses to examine invariance across gender for the baseline and cross-lagged models.

The degree of model fit for the baseline and cross-lagged models were used to make interpretations about the relations between BMI and victimization within and over time. Goodness of Fit (GOF) statistics used are the chi-square goodness of fit statistic, the comparative fit index (CFI), normed fit index (NFI), and the root mean square error of approximation (RMSEA) (Browne \& Cudeck, 1992). There are rules of thumb about acceptable levels of GOF (Marsh, Hau, \& Wen, 2004) such that RMSEA should be less than .10 to be viewed as having a reasonable fit to the data; the CFI and NFI should exceed .90; the Chi-square index should be as small as possible. Chi-square difference tests were used to compare the results for the baseline and cross-lagged models. We report standardized regression coefficients $(B)$ for boys and girls in the model. The alpha level is set to .05 throughout for the cross-lagged analyses.

\section{Results}

\section{Preliminary Analyses}

Table 3 presents all correlations between victimization and BMI at the 7 time points for boys and girls separately. First, we found stability coefficients were high for BMI for both males and females; reports of victimization were also relatively stable, even though the informants changed from mother to child at T7, when the child was aged 6 years. Second, for girls and boys there were modest, yet systematic, within-time correlations between BMI and victimization for ages 7, 8, and 10 years. Further, for girls, there were (1) across-time correlations between victimization at ages 5, 7, 8, and subsequent increases in BMI at ages 6, 
7, and 10 years, and (2) a pattern of higher BMI at ages 6, 7, and 8 and increased victimization at ages 7,8 , and 10 years of age.

To examine whether victimization was characteristic of girls with low and high BMI, we examined the curvilinear relations between these variables. Curvlinear within-time analyses yielded no significant quadratic relations for girls or boys $(B \leq .13, p \geq .63$ ) between BMI and victimization. Curvilinear analyses were also used to determine the exact associations between BMI at one time point and victimization at the following data collection wave. These analyses revealed no quadratic relations for girls or boys ( $B \leq .099, p \geq .71)$. Thus, our analyses showed only linear relations between BMI and victimization within and over time, suggesting that between the ages of $3-10$, victimization is related only to higher BMI.

Correlational analyses also revealed associations between BMI and victimization and the covariates, which were measured at each time point, but for boys only. For boys, victimization was associated with insufficient income taken at each time point ( $r \geq .08)$. Also for boys, BMI was associated with within time insufficient income $(r \geq .14)$ and lone parenting $(r \geq .12)$. For girls, there were no within time associations between insufficient income and victimization ( $r \leq .05)$, mother's education level and victimization $(r \leq .03)$, lone parenting and victimization $(r \leq .01)$. Furthermore, we found no significant within time associations between BMI and the covariates for girls ( $r$ ranges from -.001 [insufficient income] to .05 [mother's education level]).

\section{Cross-Lagged Panel Analyses}

The multi-groups baseline model included all within-time associations and stability paths, but no cross-lagged paths. The control variables that significantly correlated with victimization and BMI were included in the model; because no control variables correlated with BMI or victimization for girls, we fixed our control variables to 0 for girls. The baseline 
Running Head: VICTIMISATION AND OBESITY: LONGITUDINAL ASSOCIATIONS 16

model had a good fit to the data $(\chi 2(640)=2925.03(p<.001)$, CFI $=.92$, NFI $=.89$, RMSEA $=.05)$, but including all reciprocal cross-lagged paths produced a better fit to the data $(\chi 2$ $(576)=2761.70(p<.001), \mathrm{CFI}=.96, \mathrm{NFI}=.93, \mathrm{RMSEA}=.04)$. A significant difference was found between the baseline and cross-lagged models $\left(\Delta \chi^{2}=163.33, \Delta d f=64, p<.0001\right)$, suggesting that the cross-lagged paths improved the model. The final models for girls and boys are shown in Figures 1a and 1b respectively.

In the final model for girls (Figure 1a), the stability coefficients for BMI and victimization were significant. Also, we found some evidence of within-time associations between BMI and victimization, but only at 6,8 , and 10 years of age. We also found significant across-time associations, with higher BMI from age 6 years predicting increases in victimization over a one period. In addition, we found a number of one, two and three year cross-lagged effects, where victimization influenced changes in body mass.

In the final model for boys (Figure 1b), the stability coefficients were significant for BMI and victimization. We found no significant within-time associations between BMI and victimization, but found significant negative paths from BMI to victimization when boys were aged 7 and 8 years, suggesting that boys higher on BMI were less likely to report being victims of peers' victimization. Within the model for boys we also found within and across time associations with control variables and stability across these variables from one year to the next. Findings showed that, for boys, insufficient income was associated within and across time with peer victimization ( $B \geq 0.09, S E<.02$, $p$ 's $<.001)$ and $\mathrm{BMI}(B \geq 0.07, S E<.05, p<$ .01). BMI was also associated within and across time with lone parenting for boys $(B \geq 0.08$, $S E<.03, p<.01)$.

Following cross-lagged analyses, the Fisher $r$-to-z transformation statistic was used to test whether there were significance differences in the size of the effects across and withintime for BMI and victimization for boys and girls. Results showed that there was only one 
significant difference in the size of the within-time co-efficient and that was at age 8 years (T9), where the size of the relations was greater for girls than boys $(Z=2.18, p=.02)$. Across time, we found a significant difference in the size and direction of the effect from T8 BMI to T9 Victimization $(Z=8.12, p<.001)$ and T9 BMI and T10 Victimization $(Z=8.32, p<.001)$ with boys higher on BMI being significantly less likely to report being victimised one year later, and girls higher on BMI significantly more likely to report peer victimization. A modified version of the Pearson-Filon statistic (ZPF: Raghunathan, Rosenthal, \& Rubin, 1996) was used to investigate significant differences in coefficients found for each gender within and over time. Results for those analyses showed that, for girls, the within-time association between BMI and victimization at T9 was significantly higher than at T4, T5, T7, and $\mathrm{T} 10(\mathrm{ZPF} \geq 2.62, p \leq .01)$, and the annual across-time associations were stronger from T8-T9 and T9-T10 than from T7-T8 $(Z P F \geq 1.63, p \leq .05)$. The strongest cross-lagged effect over two or three years for girls was from T7-T10 (ZPF $\geq 2.08, p \leq .03)$. The two crosslagged effects found for boys were of similar magnitude $(Z P F=.39, p=.69)$.

In the current study, there were a large number of children classified into the $95^{\text {th }}$ percentile or above for BMI at T4-T6 (15.3\%, 44.6\%, and 73.7\% respectively for boys; 13.1\%, 31.1\% and 52.7\% for girls). The BMI data from Time 7 onwards showed that BMI was relatively stable at $10 \%$ for boys and $8 \%$ for girls. Also, from T4-T6, mothers provided reports of children's victimization, and these are seen as inferior to child reports, which we only collected from T7 onwards. Given these two limitations in design from T4-T6, we conducted further cross-lagged analyses using only data from T7-T10 and found similar results for the cross-lagged model $(\chi 2(156)=919.49, p<.001, \mathrm{CFI}=.96, \mathrm{NFI}=.94, \mathrm{RMSEA}$ $=.06)$. The size of the path coefficients remained the same. Thus, when using data from T7T10 only, we found the same effects as detailed above.

\section{Discussion}


The aim of the research was to investigate the prospective association between BMI and victimization for a sample of children aged 3 to 10 years when all within-time associations, stability coefficients, and other risk factors were controlled. The findings are consistent with predictions from the transactional model of development (Sameroff \& Mackenzie, 2003; Sameroff, 2009) because (1) the child's characteristics (gender and BMI) influenced victimization from peers, (2) BMI and victimization were shown to affect each other over time, and (3) the bidirectional influence of BMI and victimization varied in strength at different points in development. In addition, consistent with ecological theories such as Bronfenbrenner (1979), we found that this interplay did not occur in isolation from the family context.

\section{Higher BMI as a risk factor for victimization}

We found that higher BMI for girls aged six years and above increased the risk that they would be victimised by peers one year later; when girls were aged 3-6 years, we did not find that effect. Boys with higher BMI at ages seven and eight years were less likely to report victimization one or two years later. These findings expand our understanding of the relations between BMI and victimization by adding to previous empirical work that examined these associations only in children over 7 years of age (Eisenberg et al., 2006; Griffiths, et al., 2006). Our findings show different prospective relations between BMI and victimization for boys and girls highlighting the importance of examining gender differences in the peer context and the reciprocal nature between context and child characteristics such as BMI and gender over time.

There are several possible explanations for our findings, but it is likely that the negative stereotypes associated with high BMI that have been found among young children (Brylinsky \& Moore, 1994; Turnbull, et al, 2000) and the social-culture ideals of female beauty (Tang-Péronard \& Heitman 2008) influence social relationships negatively and 
increase the chances of current and future victimization. Other findings (Griffiths et al., 2011) support that notion. However, we must be cautious when interpreting these findings because of a potential limitation in our design: when the children were very young victimization was mother-reported and this may have introduced bias. Given research showing that a large proportion of adolescents and children nominate themselves as victims, but are not nominated as such by others (Salmivalli, Lagerspetz, Bjorkqvist, Osterman and Kaukialnen, 1996; Sutton and Smith, 1999), we may be missing information about children’s experiences at an early age: it is possible that an association between BMI and victimization exists for children younger than six years of age, but that the use of mother-reported victimization rather than child-self report meant that we did not detect such an association. While this is possible, parent reports are an important tool for capturing potential victimization when reliable assessments from young children are not possible.

We also examined the prospective association between lower BMI and victimization from age three to ten years based on prior findings that showed that adolescent girls with low BMI were at risk of victimization. We found that this association was not evident in childhood, suggesting that peer hostility towards thin girls is evident only once intrasexual competition strategies begin to be used during adolescence (Vaillancourt, 2013). In line with the transactional model of development, further empirical study of these effects for different samples and different ages is warranted to ensure this explanation is fully tested.

\section{Victimization predicts increases in weight}

We found that young girls from 4 years of age were likely to gain weight following victimization: we found one year cross-lagged effects from the age of 6 years, but we also found a number of two- and three-year cross-lagged effects, where victimization influenced changes in body mass. One-year cross-lagged effects have been documented previously for adolescent girls (Adams \& Bukowski, 2008), and longer-term associations have been shown 
Running Head: VICTIMISATION AND OBESITY: LONGITUDINAL ASSOCIATIONS 20

for victimization reported by boys and girls aged 14 years and BMI at 21 years of age (Mamun et al., 2012). Our findings now present a more complex picture by (1) showing this pattern of effects starts early in life, with victimization predicting weight gain for girls from as young as 3 years of age, and (2) highlighting the fact that one year may not be long enough to capture the full influence of victimization on BMI. The longer-lagged effects found for girls reveal the durable influence of victimization on annual BMI changes two and three years later, and highlight the importance of looking at influence beyond yearly intervals. The overall cross-lagged paths are modest in magnitude because the stability coefficients are high for both victimization and BMI, but there is a clear association between being victimised and increasing BMI for girls. This has important implications for future health intervention work. Whether the mechanisms linking victimization to weight gain for this sample are the same as for adolescent girls is questionable, but it is likely that a mixture of psychological and physiological factors is at work. Psychologically, victimization may influence increases in body mass by informing the developing sense of a 'fat' self (French, Story, \& Perry, 1995; Pearce et al., 2002); these negative self-concepts may increase eating behavior and discourage engagement in exercise (Adams \& Bukowski, 2008). Because the girls in the current were very young when these effects were first evident, the increase in eating behavior may represent accessibility to food, which would be provided by caregivers. It is possible that caregivers who think their child is being victimised are providing them with comfort through food or allowing their child to cope with victimization through increased food intake and/or reduced engagement in exercise. Physiological responses to stress via the hypothalamicpituitary-adrenal axis have also been implicated in the development of obesity (Tsigos \& Chrousos, 2002), and it is possible that the stress associated with being a victim of peer aggression leads to metabolic changes that predispose an individual to weight gain and 
increasing BMI. Future research could examine these possible mechanisms that explain weight gain of very young victimised children.

\section{Gender differences in the association between BMI and victimization}

There were gender differences in the relations between victimization and increases in BMI over time. Unlike the prospective association between these variables for girls, which showed that higher BMI increased victimization, associations between victimization and body mass for boys showed the opposite effect, such that higher BMI at ages 7 and 8 years predicted reduced victimization at ages 8 and 10 years. Expectations about the way girls and boys should behave might explain this: for girls, higher status is determined by thinness, whilst for boys, it is not. Studies of the relations between victimization and physical attractiveness for this age group show interesting parallel findings (Bjorkqvist et al., 1982; Salmivalli, 1998). Taken together, these studies show that, even at very young ages, girls are valued for their appearance to a greater extent than boys.

We found evidence that boys higher on BMI at ages 7 and 8 years were able to reduce their experiences of victimization, and they may have done that by using their size to intimidate peers (Griffiths et al., 2006; Janssen et al., 2004; Pearce et al., 2002). It is possible that increased BMI in boys represents greater strength in some cases rather than overweight and obesity. The family adversity variables included in this study were also important for explaining changes in victimization and BMI in boys over time, but there are other determinants of boys’ victimization, including behavior problems such as aggression (Boivin, Petitclerc, Feng, Barker, 2010) that outweigh the possible role of BMI. Thus, the social context for boys with high BMI is very different to that of girls with high BMI.

\section{Stability of victimization and BMI}

The cross-lagged coefficients reported in the current study are small in magnitude. This reflects the fact that both victimization and BMI are very stable over time for boys and 
Running Head: VICTIMISATION AND OBESITY: LONGITUDINAL ASSOCIATIONS 22

girls. Our findings support previous literature also demonstrating high levels of stability for BMI (Singh, Mulder, Twisk, Van Mechelen, \& Chinapaw, 2008) and victimization (Boivin, et al., 2010).

\section{Implications of Findings and Future Research}

Strengths of the current study were the large sample size and the longitudinal design, which provided an opportunity for the first time to examine the prospective association between victimization and BMI for children 3-10 years of age, and control the influence of family adversity variables on BMI and victimization. There are some limitations to the current study and future research should address these. First, we do not know whether the victimization reported in the current study was centred on weight-related teasing/bullying or which specific types of victimization (physical versus verbal) were experienced. We suggest that future research examines gender differences in young children and examines mediators of these associations; cross-sectional work for adolescence exists (Fox \& Farrow, 2009), but prospective research and research with young children is warranted. In addition, the construct of peer victimization needs to be qualified and put in the social context of preschool children. The power imbalance implicit in the definition of bully-victim relationships was not explicitly specified in the current study. It may also be that peer victimization partly reflects the 'giveand-take' of aggressive exchanges and the peer groups' reaction to the child's aggression rather than bullying per se. A more fundamental question, and one that cannot be answered by the present study, concerns the nature of peer victimization experiences in preschool as they relate to such experiences in middle and late childhood. Fine-grained observational studies are needed to document the social dynamics of peer victimization in preschool, and examine the relations between victimization and BMI.

Second, the use of different informants of victimization at different times in the prospective study could be viewed as a limitation, particularly given that the effects of BMI 
Running Head: VICTIMISATION AND OBESITY: LONGITUDINAL ASSOCIATIONS 23

on future victimization are only evident when the child self-reports on victimization. These effects could represent real differences in the associations over time, but we cannot be certain of that because different informants were asked to provide victimization data before the child was 6 years of age. It is common practice to ask adults about young children’s victimization (Card et al, 2008; Shakoor et al., 2011) because they provide more reliable information than children themselves, who may not have adequate cognitive abilities to understand the concepts being assessed (Ladd \& Kochenderfer-Ladd, 2002; Measelle, et al., 1998). Even so, our design could be improved by using both parent- and child-self report data for children over the age of six.

Third, we have investigated only victimization by peers. Given evidence that obese/overweight children are victimised by teachers and family members (Eisenberg et al., 2003; Goldfield et al., 2010; Puhl \& King, 2013), future studies may usefully explore how differences in attitudes towards obese girls and boys from parents, educators, and healthcare providers predict changes in BMI over time.

A final consideration is the need to control for variables other than those related to family adversity that may qualify the association between victimization and high BMI. For example, longitudinal research links internalizing problems with peer victimization (Zwierzynska, Wolke, \& Lereya, 2013) and obesity (Bradley, Houts, Nader, O’Brien, Belsky, \& Crosnoe, 2008) and it is possible that internalizing problems partially explain why some children are more likely to be victimized and overweight than others. Furthermore, observed maternal responsiveness in infancy has been found to be associated with high BMI at 15 years of age (Anderson, Gooze, Lemeshow, \& Whitaker, 2012) and future work may want to examine whether maternal responsiveness moderates the relations between victimization and BMI over time.

\section{Conclusions}


Running Head: VICTIMISATION AND OBESITY: LONGITUDINAL ASSOCIATIONS 24

These current findings demonstrate that, for girls, high BMI from age 6 years contributes to being victimized, while victimization between 3 and 10 years of age contributes to increases in BMI. Thus, having a high BMI for girls was an important predictor of victimization; being victimised also predicted weight gain for girls and this has obvious health consequences for girls who became overweight and for girls already overweight or obese. In contrast, higher BMI for boys was related to reduced victimization for boys aged 7 and 8 years of age, suggesting that boys may use their increased mass to intimidate perpetrators of aggression. From a clinical perspective there is a need to determine the mechanisms underlying changes in body mass produced by victimization for girls, and find out why high BMI for girls and boys in middle childhood has such different effects on future victimization. In terms of intervention, the current study provides (1) evidence of who is at risk of being victimised for being overweight (girls) and (2) a better understanding of who is more vulnerable to the effects of victimization via increases in BMI (obese and overweight girls). The study findings highlight the importance of reducing victimization for girls high on BMI starting from early childhood. 
Running Head: VICTIMISATION AND OBESITY: LONGITUDINAL ASSOCIATIONS 25

Acknowledgements: This research was based on the Québec Longitudinal Study of Child Development (QLSCD), and was supported by the Institut de la statistique du Québec, the Québec Ministry of Health and Social Services, the Québec Ministry of Families and Seniors, the Lucie et André Chagnon Foundation, the Fonds Québécois de la Recherche sur la Société et la Culture (FQRSC), the Social Science and Humanities Research Council of Canada (SSHRC), the Canadian Institutes for Health Research (CIHR), the Research Unit on Children's Psychosocial Maladjustment (GRIP), and the Ste. Justine’s Hospital Research Center. Michel Boivin is supported by the Canada Research Chair Program. We are grateful to the participating parents, children, teachers, and schools of the QLSCD. We thank the Institut de la statistique du Québec, Mireille Jetté, Bertrand Perron, and the GRIP staff for data collection and management.

Conflict of Interest /disclosure statement: We have no potential conflict of interests pertaining to 'Aggressive Behavior'. 
Running Head: VICTIMISATION AND OBESITY: LONGITUDINAL ASSOCIATIONS 26

\section{References}

Adams, R.E, \& Bukowski, W.M. (2008). Peer victimization as a predictor of depression and body mass index in obese and non-obese adolescents. Journal of Child Psychology and Psychiatry, 49, 858-866. doi:10.1111/j.1469-7610.2008.01886.x

Anderson, S. E., Gooze, R. A., Lemeshow, S., \& Whitaker, R. C. (2012). Quality of Early Maternal-Child Relationship and Risk of Adolescent Obesity. Pediatrics, 129, 132-140. doi:10.1542/peds.2011-0972

Arbuckle, J.L. (2008). AMOS 17 User’s Guide, Chicago: SPSS Inc.

Archer, J. (2004). Sex differences in aggression in real-world settings: A meta-analytic review. Review of General Psychology, 8, 291-322. doi:10.1037/1089-2680.8.4.291.

Barker, E.D., Boivin, M., \& Brendgen, M. (2008). Predictive validity and early predictors of peer victimization trajectories in preschool. Archives of General Psychiatry, 65, 11851192. doi:10.1001/archpsyc.65.10.1185

Bierman, K. (2004). Peer rejection: Developmental processes and intervention strategies. New York, London: Guildford Press.

Bjorkqvist, K., Ekman, K., \& Lagerspetz, K. (1982). Bullies and victims: Their ego picture, ideal ego picture and normative ego picture. Scandinavian Journal of Psychology, 23, 307-313. doi:10.1111/j.1467-9450.1982.tb00445.x

Boivin, M., Petitclerc, A., Feng, B., \& Barker, E.D. (2010). The developmental trajectories of peer victimization in middle to late childhood and the changing nature of their correlates. Merrill Palmer Quarterly, 56, 231-260. doi:10.1353/mpq.0.0050

Boneberger, A., Von Kries, R., Milde-Busch, A., Bolte, G., Rochat, M.K., \& Rückinger, S. (2009). Association between peer relationship problems and childhood overweight/obesity. Acta Paediatrica, 98, 1950-1955. doi:10.1111/j.1651-2227.2009.01484.x 
Running Head: VICTIMISATION AND OBESITY: LONGITUDINAL ASSOCIATIONS 27

Bowker, J.C., Spencer, S.V., \& Salvy, S.J. (2010). Examining how overweight adolescents process social information: The significance of friendship quality. Journal of Applied Developmental Psychology, 31, 231-237. doi:10.1016/j.appdev.2010.01.001

Bradley, R.H., Houts, R., Nader, P.R., O’Brien, M., Belsky, J., \& Crosnoe, R. (2008). The relationship between body mass index and behavior in children. Journal of Pediatrics, 153, 629-34. doi:10.1016/j.jpeds.2008.05.026

Brofenbrenner, U. (1979). The ecology of human development: Experiments by nature and design. Cambridge, MA: Harvard University Press.

Brylinsky, J.A., \& Moore, J. C. (1994). The identification of body build stereotypes in young children. Journal of Research on Personality, 28, 170- 181. 10.1006/jrpe.1994.1014

Card, N. A., Stucky, B. D., Sawalani, G. M., \& Little, T. D. (2008). Direct and indirect aggression during childhood and adolescence: A meta-analytic review of gender differences, intercorrelations, and relations to maladjustment. Child Development, 79, 1185-1229. doi:10.1111/j.1467-8624.200801184.x

Cicchetti, D., \& Lynch, M. (1993). Toward an ecological / transactional model of community violence and child maltreatment: Consequences for children's development. Psychiatry, 5, 96-118.

Desrosiers, H., Dubois, L, \& Bédard, B. (2005). Enquête de nutrition auprès des enfants québécois de 4 ans. Québec: Institut de la Statistique du Québec.

Dubois, L., \& Girard, M. (2007). Accuracy of maternal reports of preschoolers’ weights and heights as estimates of BMI values. International Journal of Epidemiology, 36, 132138. doi:10.1093/ije/dyl281

Eisenberg, M.E., Neumark-Sztainer, D., Haines, J.H., \& Wall, M. (2006) Weight-teasing and emotional well being in adolescents: longitudinal finding from Project EAT. Journal of Adolescent Health, 38, 675-683. doi: 10.1016/j.jadohealth.2005.07.002 
Running Head: VICTIMISATION AND OBESITY: LONGITUDINAL ASSOCIATIONS 28

Faith, M.S., Leone, M.A., Ayers, T.S., Heo, M., \& Pietrobelli, A. (2002). Weight criticism during physical activity, coping skills, and reported physical activity in children. Pediatrics, 110, e23.

French, S.A., Story, M., \& Perry, C.L. (1995). Self-esteem and obesity in children and adolescents: a literature review. Obesity Research, 3, 479-490. doi:10.1002/j.1550-8528.1995.tb00179.x

Falkner, N. H., Neumark-Sztainer, D., Story, M., Jeffery, R. W., Beuhring, T., Resnick, M. D. (2001) Social, educational, and psychological correlates of weight status in adolescents. Obesity Research, 9, 32-42. doi:10.1038/oby.2001.5

Fox, C. L., \& Farrow, C. V. (2009). Global and physical self-esteem and body dissatisfaction as mediators of the relationship between weight status and being a victim of bullying. Journal of Adolescence, 32, 1287-1301. doi:10.1016/j.adolescence.2008.12.006

Gibson, L.Y., Byrne, S.M., Blair, E., Davis, A., Jacoby, P., \& Zubrick, S.R. (2008) Clustering of psychological symptoms in overweight children. Australian and New Zealand Journal of Psychiatry, 42, 118-125. doi: 10.1080/00048670701787560

Griffiths, L.J., Dezateux, C., \& Hill, A. (2011). Is obesity associated with emotional and behavioral problems in children? Findings from the Millennium Cohort Study. International Journal of Pediatric Obesity, 6, 423-432. doi:10.3109/17477166.2010.526221

Griffiths, L.J., \& Page, A.S. (2008). The impact of weight-related victimization on peer relationships: the female adolescent perspective. Obesity, 16, 39-45. doi: 10.1038/oby.2008.449

Griffiths, L.J., Wolke, D., Page A.S., Horwood, J.P., \& the ALSPAC study team (2006). Obesity and bullying: Different effects for boys and girls. Archives of Disease in Childhood, 91, 121-125. doi:10.1136/adc.2005.072314 
Running Head: VICTIMISATION AND OBESITY: LONGITUDINAL ASSOCIATIONS 29

Grow, H.M.G, Cook, A.J., Arterbarn, D.E., Saelens, B.E., Drewnowski, A., \& Lozano, B.E. (2010). Child obesity associated with social disadvantage of children’s neighborhoods. Social Science and Medicine, 71, 584-591. doi:10.1016/j.socscimed.2010.04.018

Hammer, L.D., Kraemer, H.C., Wilson, D.M., Ritter, P.L., \& Dornbusch, S.M. (1991). Standardized percentile curves of body-mass index for children and adolescents. American Journal of Disease in Childhood, 145, 259-263. doi:10.1001/archpedi.1991.02160030027015

Janssen, I., Craig, W.M., Boyce, W.F., \& Pickett, W. (2004). Association between overweight and obesity with bullying behaviors in school-aged children. Pediatrics, 113, 1187-1194.

Jensen, C. D., \& Steele, R. G. (2009). Brief report: Body dissatisfaction, weight criticism, and selfreported physical activity in preadolescent children, Journal of Pediatric Psychology, 34, $822-826$.

Ladd, G. W., \& Kochenderfer-Ladd, B. (2002). Identifying victims of peer aggression from early to middle childhood: Analysis of cross-informant data for concordance, estimation of relational adjustment, prevalence of victimization, and characteristics of identified victims. Psychological Assessment, 14, 74-96.

Latner, J., \& Stunkard, A. (2003). Getting worse: the stigmatization of obese children. Obesity Research, 11, 452- 456. doi: 10.1038/oby.2003.61

Little, R. J. A. (1988). A test of missing completely at random for multivariate data with missing values. Journal of the American Statistical Association, 83, 1198-1202.

Little, R.J.A., \& Rubin, D.B. (1987). Statistical analysis with missing data. New York: John Wiley.

Lumeng, J.C., Forrest, P., Appugliese, D.P., Kaciroti, N., Corwyn, R.F., \& Bradley, R.H. (2010). Weight status as a predictor of being bullied in third through to sixth grades. Pediatrics, 125, 1301-1307. doi: 10.1542/peds.2009-0774 
Running Head: VICTIMISATION AND OBESITY: LONGITUDINAL ASSOCIATIONS 30

Mamun, A.A., O’Callaghan, M.J., Williams, G.M., \& Najman, J.M. (2013). Adolescents bullying and young adults body mass index and obesity: A longitudinal study. International journal of obesity, 37, 1140-1146. doi:10.1038/ijo.2012.182

Marsh, H.W., Hau, K.T., \& Wen, Z.L. (2004). In search of golden rules: Comment on hypothesis testing approaches to setting cutoff values for fit indexes and dangers in overgeneralising Hu \& Bentler (1999) findings. Structural Equation Modeling, 11, 320341. doi: 10.1207/s15328007sem1103_2

Measelle, J. R., Ablow, J. C., Cowan, P. A., \& Cowan, C. P. (1998). Assessing young children's views of their academic, social, and emotional lives: an evaluation of the selfperception scales of the Berkeley Puppet Interview. Child Development, 69, 1556-1576.

Monks, C. P., Ortega, R., \& Torrado, E. (2002). Unjustified aggression in a Spanish preschool. Aggressive Behavior, 28, 458-476. doi:10.1002/ab.10032

Monks, C. P., Smith, P. K., \& Swettenham, J. (2003). Aggressors, victims and defenders in preschool: peer-, self- and teacher-reports. Merrill-Palmer Quarterly, 49, 453-469.

Neumark-Sztainer, D., Falkner, N., Story, M., Perry, C., Hannan, P. J., Mulert, S. (2002). Weight-teasing among adolescents: Correlations with weight status and disordered eating behaviors, International Journal of Obesity, 26, 123-131.

Pearce, M.J., Boegers, J., \& Prinstein, M.J. (2002). Adolescent obesity, overt and relational peer victimization, and romantic relationships. Obesity Research, 10, 386-393. doi: 10.1038/oby.2002.53

Puhl, R., \& Brownell, K.D. (2001). Bias, discrimination, and obesity. Obesity Research, 9, 788805. doi: 10.1038/oby.2001.108

Raghunathan, T. E., Rosenthal, R., \& Rubin, D. B. (1996). Comparing correlated but nonoverlapping correlations. Psychological Methods, 1, 178-183. 
Running Head: VICTIMISATION AND OBESITY: LONGITUDINAL ASSOCIATIONS 31

Salmivalli, C. (1998). Intelligent, attractive, well-behaving, unhappy: The structure of adolescents' self-concept and its relations to their social behavior. Journal of Research on Adolescence, 8, 333-354. doi:10.1207/s15327795jra0803_3

Salmivalli, C., Lagerspetz, K., Bjorkqvist, K., Osterman, K., \& Kaukiainen, A. (1996).

Bullying as a group process: Participant roles and their relations to social status within the group. Aggressive Behavior, 22, 1-15. doi:10.1002/(SICI)10982337(1996)22:1<1::AID-AB1>3.0.CO;2-T

Sameroff, A. (2009). The transactional model of development: How children and contexts shape each other. Washington, DC US: American Psychological Association. doi:10.1037/11877-000

Sameroff, A. J. \& Chandler, M. J. (1975). Reproductive risk and the continuum of caretaker casualty. In F. D. Horowitz (Ed.), Review of child development research (Vol. 4). Chicago: University of Chicago Press.

Sameroff, A.J. \& MacKenzie, M.J. (2003). Research strategies for capturing transactional models of development: The limits of the possible. Development and Psychopathology, 15, 613-640.

Schafer, J. L., \& Graham, J. W. (2002). Missing data: our view of state of the art. Psychological Methods, 7, 147-177. http://dx.doi.org/10.1037/1082-989X.7.2.147.

Schreier, A., Wolke, D., Thomas, K., Horwood, J., Hollis, C., Gunnell, D., Lewis, G., Thompson, A., Zammit, S., Duffy, L., Salvi, G. \& Harrison, G. (2009). Prospective study of peer victimization in childhood and psychotic symptoms in a nonclinical population at age 12 years. Archives of General Psychiatry, 66, 527-536. doi:10.1001/archgenpsychiatry.2009.23

Shakoor, S., Jaffee, S. R., Andreou, P., Bowes, L., Ambler, A. P., Caspi, A., Moffitt, T. E., \& Arseneault, L. (2011). Mothers and children as informants of bullying victimization: 
Running Head: VICTIMISATION AND OBESITY: LONGITUDINAL ASSOCIATIONS 32

Results from an epidemiological cohort of children. Journal of Abnormal Child

Psychology, 39, 379-387. DOI 10.1007/s10802-010-9463-5.

Singh, A.S., Mulder, C., Twisk, J.W.R., Van Mechelen, W., \& Chinapaw, M.J.M. (2008). Tracking of childhood overweight into adulthood: a systematic review of the literature. Obesity Review, 9, 474-488. doi:10.1111/j.1467-789X.2008.00475.x

Strauss, R.S., \& Pollack, H.A. (2003). Social marginalization of overweight adolescents. Archives of Pediatric Adolescent Medicine, 157, 746 -52. doi:10.1001/archpedi.157.8.746

Sutton, J., \& Smith, P. K. (1999). Bullying as a group process: An adaptation of the participant role approach. Aggressive Behavior, 25, 97-111. doi:10.1002/(SICI)10982337(1999)25:2<97::AID-AB3>3.0.CO;2-7

Sweeting, H., Wright, C., \& Minnis, H. (2005). Psychosocial correlates of adolescent obesity, slimming down' and 'becoming obese'. Journal of Adolescent Health, 37, 409.e9-409.e17.

Tang-Péronard, J.L., \& Heitman, B.L. (2008). Stigmatization of obese children and adolescents, the importance of gender. Obesity Review, 9, 522-534. doi:10.1111/j.1467-789X.2008.00509.x

Tremblay, R.E. (2000). The development of aggressive behavior during childhood: what have we learned in the past century. International Journal of Behavioral Development, 24, 129-141.

Tsigos, C. \& Chrousos, G. P. (2002). Hypothalamic-pituitary-adrenal axis, neuroendocrine factors and stress. Journal of Psychosomatic Research, 53, 865-871. doi:S0022-3999(02)00429-4

Ttofi, M., Farrington, D., Losel, F., \& Loeber, R. (2011). Do the victims of school bullies tend to become depressed later in life? A systematic review and meta-analysis of longitudinal studies. Journal of Aggression, Conflict and Peace Research, 3, 63-73. doi:10.1108/17596591111132873

Turnbull, J.D., Heaslip, S., \& McLeod, H.A. (2000). Pre-school children’s attitudes to fat and normal male and female stimulus figures. International Journal of Obesity. 24, 17051706. 10.1038/sj.ijo.0801462 
Running Head: VICTIMISATION AND OBESITY: LONGITUDINAL ASSOCIATIONS 33

Vaillancourt T. (2013) Do human females use indirect aggression as an intrasexual competition strategy? Philisophical Transcriptions of the Royal Society B 368: 20130080. http://dx.doi.org/10.1098/rstb.2013.0080

Wang, J., Iannotti R.J., \& Luk, J.W. (2010) Bullying victimization among underweight and overweight U.S. youth: differential associations for boys and girls. Journal of Adolescent Health, 47, 99-101. doi:10.1016/j.jadohealth.2009.12.007)

Wardle, J., Volz, C., \& Golding, C. (1995). Social variation in attitudes to obesity in children. International Journal of Obesity, 19, 562-569.

Winsper, C., Lereya, T., Zanarini, M., Wolke, D. (2012). Involvement in bullying and suiciderelated behavior at 11 years: A prospective birth cohort study. Journal of the American Academy of Child \& Adolescent Psychiatry, 51, 271-282. doi:10.1016/j.jaac.2012.01.001

Zeller, M.H., Reiter-Purtill, J., \& Ramey, C. (2008). Negative peer perceptions of obese perceptions in the classroom environment. Obesity, 16, 755-762. doi: 10.1038/oby.2008.4

Zwierzynska, K., Wolke, D., \& Lereya, T. S. (2013). Peer victimization in childhood and internalizing problems in adolescence: A prospective longitudinal study. Journal of Abnormal Child Psychology, 41, 309-323. doi:10.1007/s10802-012-9678-8 
Running Head: VICTIMISATION AND OBESITY: LONGITUDINAL ASSOCIATIONS 34

Table 1. Characteristics of the final sample

$\begin{array}{ccc}\text { Time point } & \text { Age of participants (SD) } & \mathrm{n}= \\ \text { T4 } & \text { 3.4 years (0.58 months) } & 1950 \\ \text { T5 } & \text { 4.1 years (3.12 months) } & 1944 \\ \text { T6 } & \text { 5.1 years (3.12 months) } & 1759 \\ \text { T7 } & \text { 6.2 years (3.05 months) } & 1492 \\ \text { T8 } & \text { 7.2 years (3.06 months) } & 1451 \\ \text { T9 } & \text { 8.1 years (2.60 months) } & 1334 \\ \text { T10 } & \text { 10.1 years (2.60 months) } & \end{array}$

\section{Demographics of final sample used in the current study}

Boys \% $\quad 47$

French-speaking families \% $\quad 81$

Mother's age in years at T1 28.8

Father's age in years at T1 31.8

Mothers did not hold a high school degree \% T4 17

Fathers did not hold a high school degree \% T4 20

Mother had a university degree \% $\quad$ T4 28

Father had a university degree \% $\quad$ T4 26

Income $\leq$ Canadian Dollars \$30 000 (US \$29 451) \% T4 28

Income $\geq \mathrm{CaD} \$ 60000$ (US \$58 902) \% T4 0.6

$\begin{array}{ll}\text { Households headed by lone parent \% T4 } & 7\end{array}$

Attended child-care \% at T4 100 
Running Head: VICTIMISATION AND OBESITY: LONGITUDINAL ASSOCIATIONS 35

Table 2: Descriptive statistics for study variables.

\begin{tabular}{lcccc}
\hline & Age in years & Boys & Girls & Alpha \\
& & \multicolumn{1}{c}{ M (SD) } & M (SD) & \\
\hline V T4 & 3.4 & $1.41(1.45)$ & $1.23(1.31)$ & .61 \\
V T5 & 4.1 & $1.39(1.65)$ & $1.42(1.57)$ & .65 \\
V T6 & 5.1 & $1.80(1.79)$ & $1.68(1.83)$ & .63 \\
V T7 & 6.2 & $.97(1.15)$ & $.72(1.14)$ & .64 \\
V T8 & 7.2 & $1.43(1.67)$ & $.96(1.50)$ & .51 \\
V T9 & 8.1 & $1.21(1.63)$ & $.83(1.48)$ & .72 \\
V T10 & 10.1 & $1.54(1.89)$ & $1.00(1.46)$ & .77 \\
\hline BMI T4 & 3.4 & $15.83(2.20)$ & $15.35(2.13)$ & - \\
BMI T5 & 4.1 & $17.43(2.53)$ & $16.86(2.44)$ & - \\
BMI T6 & 5.1 & $19.58(3.13)$ & $19.19(3.05)$ & - \\
BMI T7 & 6.2 & $15.85(1.87)$ & $15.78(2.09)$ & - \\
BMI T8 & 7.2 & $16.12(2.26)$ & $16.05(2.29)$ & - \\
BMI T9 & 8.1 & $16.82(2.58)$ & $16.76(2.67)$ & - \\
BMI T10 & 10.1 & $18.45(3.23)$ & $18.46(3.26)$ & - \\
\hline
\end{tabular}

Notes. V= Victimization; BMI = Body Mass Index. Mothers acted as informants of victimization at T4, T5, and T6; children provided self-reports of victimization from T7 onwards when they were aged 6 years. BMI was calculated as weight $[\mathrm{kg}] /$ height $[\mathrm{m}] 2$, and these BMI values were converted to BMI z-scores using national reference data to adjust for age and sex. Time points are one year apart from T4-T9, but there is a two-year gap between T9 and T10. T10 is referred to as T11 in the QLSCD archive. 
Running Head: VICTIMISATION AND OBESITY: LONGITUDINAL ASSOCIATIONS 36

Table 3: Correlations between Victimization and BMI

\begin{tabular}{|c|c|c|c|c|c|c|c|c|c|c|c|c|c|c|c|}
\hline & Age in years & VT4 & VT5 & VT6 & VT7 & VT8 & VT9 & VT10 & BMI T4 & BMI T5 & BMI T6 & BMI T7 & BMI T8 & BMI T9 & $\begin{array}{l}\text { BMI } \\
\text { T10 }\end{array}$ \\
\hline VT4 & 3.4 & & $.37 * * *$ & $.30 * *$ & $.25 * *$ & .002 & .003 & .05 & .02 & .03 & .03 & .01 & .009 & .02 & .002 \\
\hline VT5 & 4.1 & $.39 * *$ & & $.39 * *$ & $.27 * *$ & .05 & .01 & $.11^{*}$ & -.04 & -.05 & .02 & .07 & .04 & .07 & .06 \\
\hline VT6 & 5.1 & $.33^{* *}$ & $.38 * *$ & & $.35^{* *}$ & .06 & .04 & $.18^{* *}$ & .004 & .03 & .07 & $.12^{* * *}$ & $.08^{*}$ & $.13 * * *$ & $.11^{* *}$ \\
\hline VT7 & 6.2 & $.30 * *$ & $.10^{*}$ & $.13^{* *}$ & & $.21 * * *$ & $.21^{* * *}$ & $.17 * * *$ & .02 & .01 & -.02 & .07 & .07 & .03 & .06 \\
\hline VT8 & 7.2 & .06 & .06 & .07 & $.28^{* *}$ & & $.37 * * *$ & $.29 * * *$ & $.10^{* *}$ & $.12^{* *}$ & $.12^{* *}$ & $.15^{* * *}$ & $.14^{* * *}$ & $.16^{* * *}$ & $.16^{* * *}$ \\
\hline VT9 & 8.1 & .04 & .03 & .06 & $.26^{* *}$ & $.44 * * *$ & & $.36 * * *$ & $.08 *$ & .06 & .04 & $.19 *$ & $.12 * * *$ & $.14 * * *$ & $.13^{* * *}$ \\
\hline VT10 & 10.1 & .07 & $.11^{* *}$ & $.15^{* *}$ & .16 & $.28^{* * *}$ & $.34^{* *}$ & & .04 & .02 & .08 & $.13^{*}$ & $.11^{*}$ & $.13^{*}$ & $.19^{* *}$ \\
\hline BMI T4 & 3.4 & .04 & .03 & .002 & -.04 & .06 & $.12 *$ & .00 & & $.77 * * *$ & $.72 * * *$ & $.53 * * *$ & $.54 * * *$ & $.51^{* * *}$ & $.45^{* * *}$ \\
\hline BMI T5 & 4.1 & .06 & -.009 & .001 & -.06 & .04 & $-.08 *$ & -.01 & $.77^{* * *}$ & & $.80^{* * *}$ & $.54 * * *$ & $.58^{* * *}$ & $.55^{* * *}$ & $.53^{* * *}$ \\
\hline BMI T6 & 5.1 & .05 & -.003 & .04 & -.04 & $.12^{*}$ & .07 & -.05 & $.71^{* * *}$ & $.78^{* * *}$ & & $.65^{* * *}$ & $.71^{* * *}$ & $.69 * * *$ & $.65^{* * *}$ \\
\hline BMI T7 & 6.2 & $.08^{*}$ & -.018 & .06 & .005 & .03 & .07 & -.03 & $.56^{* * *}$ & $.60 * * *$ & $.72^{* * *}$ & & $.79 * * *$ & $.79 * * *$ & $.73^{* * *}$ \\
\hline BMI T8 & 7.2 & .07 & -.001 & .06 & .03 & $.15^{*}$ & $.12 *$ & -.01 & $.52 * * *$ & $.57 * * *$ & $.69 * * *$ & $.79 * * *$ & & $.83 * * *$ & $.79^{* * *}$ \\
\hline BMI T9 & 8.1 & $.08 *$ & .019 & .06 & -.03 & .04 & $.09 *$ & .06 & $.51^{* * *}$ & $.54 * * *$ & $.67 * * *$ & $.80 * * *$ & $.81^{* * *}$ & & $.89^{* * *}$ \\
\hline BMI T10 & 10.1 & .07 & .04 & .05 & -.04 & .06 & $.08 *$ & $.10^{*}$ & $.44^{* *}$ & $.50 * * *$ & $.61 * * *$ & $.73 * * *$ & $.75^{* * *}$ & $.88^{* * *}$ & \\
\hline
\end{tabular}


Notes. V= Victimization; BMI = Body Mass Index; Correlations for girls appear in upper triangle and correlations for boys are in the lower triangle. ${ }^{*} p<.05 ; * * p<.01 ; * * * p<.001$. Mothers provided victimization information at T4, T5, and T6; children provided self-reports of victimization from T7 onwards when they were aged 6 years. BMI was calculated as weight $[\mathrm{kg}] /$ height $[\mathrm{m}] 2$, and these BMI values were converted to BMI z-scores using national reference data to adjust for age and sex. Time points are one year apart from T4-T9, but there is a twoyear gap between T9 and T10. T10 is referred to as T11 in the QLSCD archive. 
Figure 1a. Final cross-lagged panel model for girls. Notes: ${ }^{*} \mathrm{p}<.05,{ }^{* *} \mathrm{p}<.01, * * *$ $\mathrm{p}<.001$. Standardised coefficients are reported. Family adversity measures were included in the model for girls and showed stability over time; they were not associated with either BMI or victimization between or across time so are not included in the figure below. Mothers provided victimization information when the child was 3, 4 and 5 years of age; when the child was $6,7,8$, and 10 , they provided self-report information of victimization. T10 is referred to as T11 in the QLSCD archive.

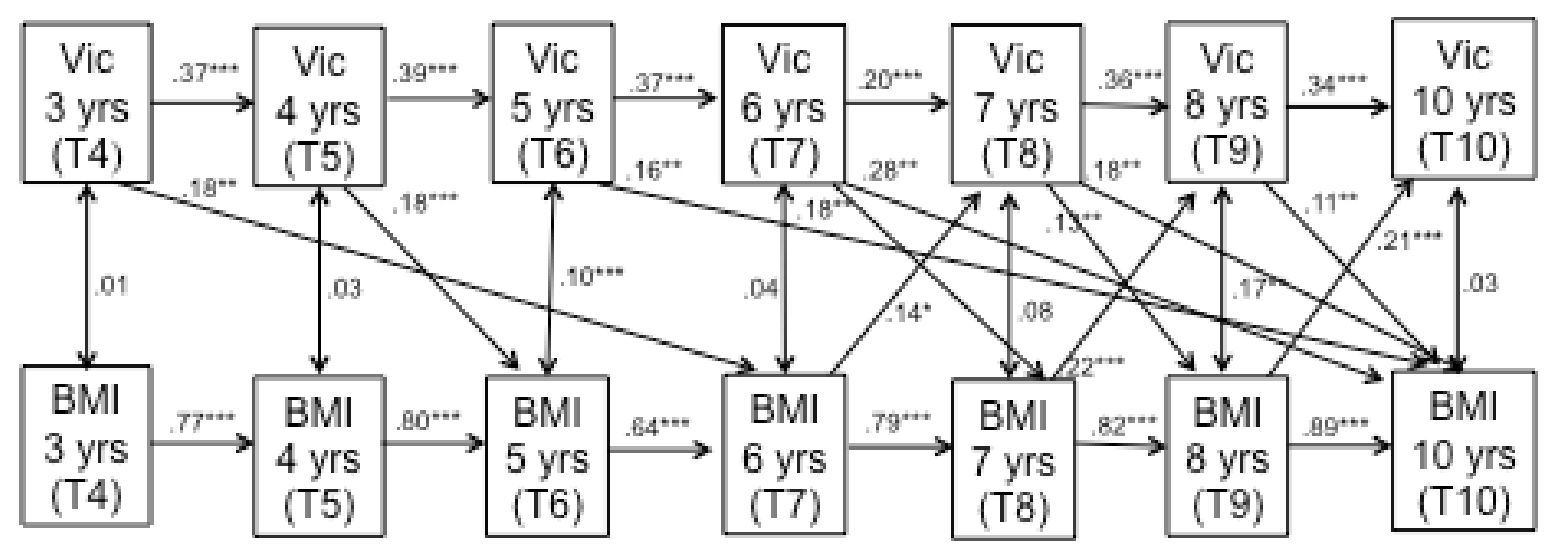


Figure 1b. Final model for boys. Notes: ${ }^{* *} \mathrm{p}<.01,{ }^{* * *} \mathrm{p}<.001$. Standardised coefficients are reported. For boys, insufficient income was associated within time with peer victimization and BMI; insufficient income was also correlated across-time with victimization at T4-T5 and T9-T10. BMI was also associated within time with lone parenting for boys, and across time from T4-T5. In addition, there was an across-time association between lone parenting at T4 and victimization of child at T5 (a) and a within time association between lone parenting and peer victimization at T4 only (b). Estimates related to those coefficients for family adversity variables are not included in the figure for ease of presentation. Also for ease of presentation, insufficient income is noted twice in the figure because it was associated with both victimization and BMI for boys. Mothers provided victimization information when the child was 3, 4 and 5 years of age; when the child was $6,7,8$, and 10, they provided self-report information of victimization. T10 is referred to as T11 in the QLSCD archive.

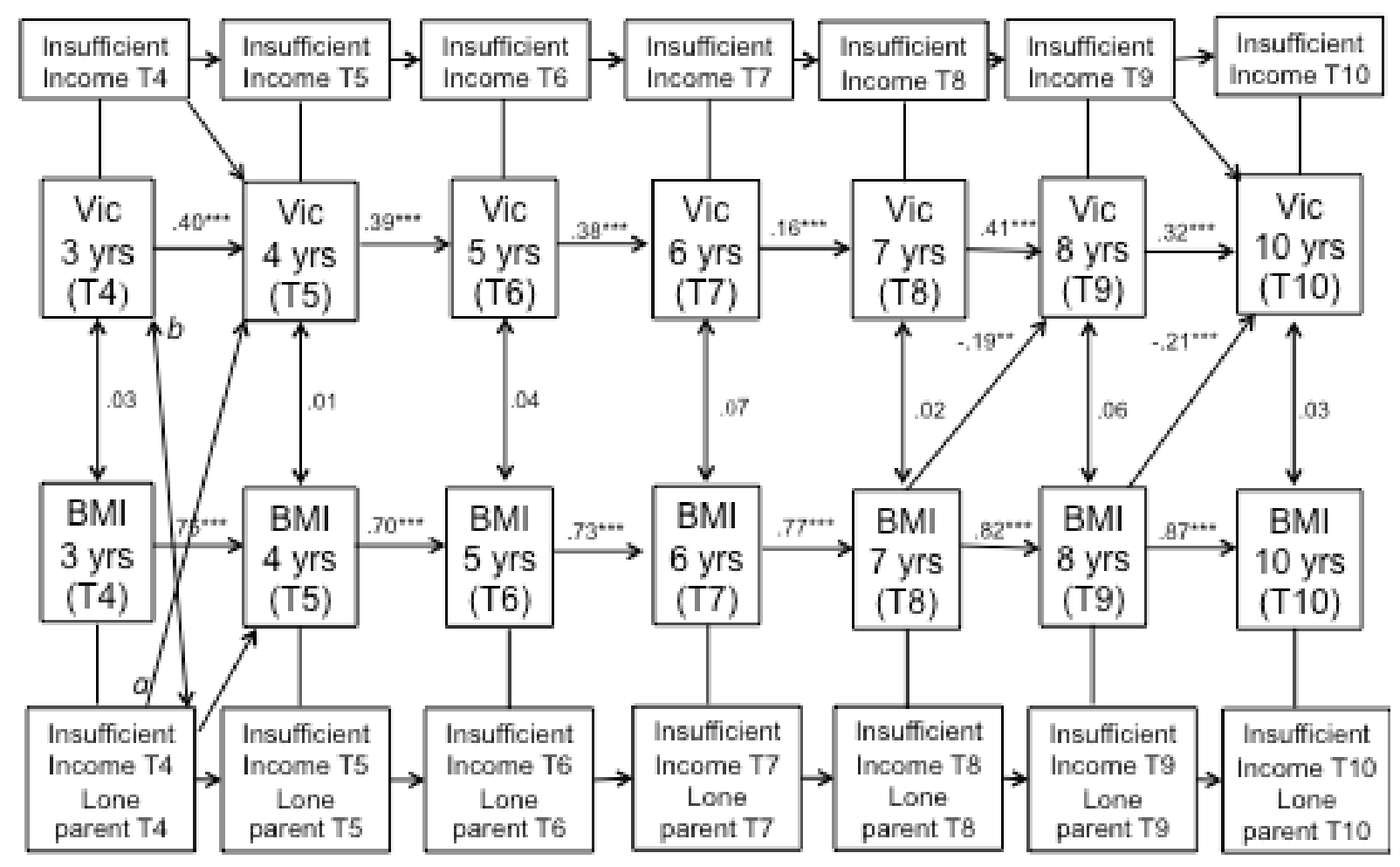

